Article

\title{
Coastal Innovation Imperative
}

\section{Bruce C. Glavovic}

Resource and Environmental Planning Programme, Massey University, Palmerston North 4442, New Zealand; E-Mail: b.glavovic@massey.ac.nz; Tel.: +64-6-356-9099; Fax: +64-6-350-5737

Received: 21 December 2012; in revised from: 17 January 2013 / Accepted: 15 February 2013 / Published: 4 March 2013

\begin{abstract}
This is the second of two articles that explores the coastal innovation paradox and imperative. Paradoxically, innovation is necessary to escape the vulnerability trap created by past innovations that have degraded coastal ecosystems and imperil coastal livelihoods. The innovation imperative is to reframe and underpin business and technology with coherent governance innovations that lead to social transformation for coastal sustainability. How might coastal management help to facilitate this transition? It is argued that coastal management needs to be reconceptualised as a transformative practice of deliberative coastal governance. A foundation comprising four deliberative or process outcomes is posited. The point of departure is to build human and social capital through issue learning and improved democratic attitudes and skills. Attention then shifts to facilitating community-oriented action and improving institutional capacity and decision-making. Together, these endeavours enable improved community problem-solving. The ultimate process goal is to build more collaborative communities. Instituting transformative deliberative coastal governance will help to stimulate innovations that chart new sustainability pathways and help to resolve the coastal problématique. This framework could be adapted and applied in other geographical settings.
\end{abstract}

Keywords: coastal innovation imperative; coastal management; transformative innovation; sustainable coastal development; deliberative coastal governance

\section{Introduction}

The coast is the frontline of humanity's struggle for sustainability. As argued in the previous article [1], an innovation paradox must be confronted at the coast: new modalities of innovation are necessary to escape the vulnerability trap set by past innovation that has yielded unsustainable 
outcomes. This article focuses on the imperative to reframe and underpin future business and technological development with governance innovations that lead to social transformation for coastal sustainability. This research builds on coastal management scholarship and explores the pivotal role of innovation in conceptualizing and operationalising a transformative practice of coastal governance. A conceptual framework is proposed that builds upon the Orders of Outcome approach developed by Olsen and colleagues between 2002 and 2009 [2-7] (see Figure 1).

Figure 1. Orders of coastal governance outcomes (After Olsen et al. [7]).

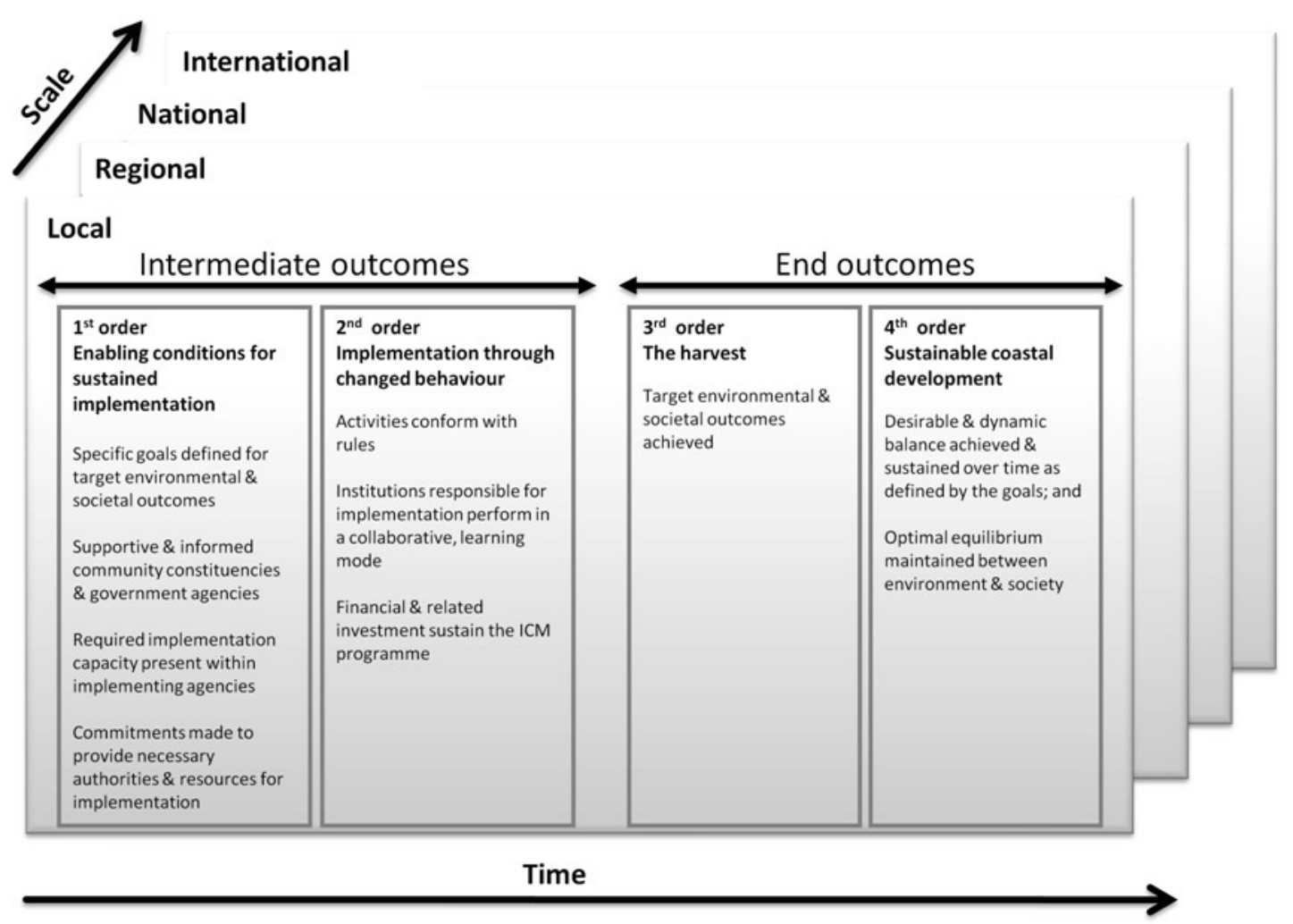

Coastal management initiatives aim to promote sustainability and provide practical mechanisms for integrating disciplinary analysis and sectoral activities to enable stakeholders to reconcile divergent interests in the face of rapid change. The Orders of Outcomes framework recognizes that these initiatives are long-term endeavours (over decades rather than a few years) that necessitate changes in the state of the coupled social-ecological coastal system from prevailing unsustainable conditions towards more sustainable outcomes. Such changes in state require changes in the behaviour of stakeholders organizations and institutions [3]. Assembling the first order outcomes sets the stage for behavioural changes that facilitate implementation of a plan of action, develop requisite institutional capacity and move towards higher order outcomes. However, enduring progression beyond first order outcomes has proved to be extremely difficult: the coastal problématique persists and coastal management is at sea. As explained by Glavovic [1], the general failure of coastal management efforts to yield sustainable outcomes is due, in large measure, to efforts being based on short-term isolated episodes that are subsumed by long-term dominant governance processes that reinforce the status quo and perpetuate unsustainable practices. Consequently, coastal innovation is imperative. This article proposes a transformative practice of deliberative coastal governance, founded on four process outcomes that 
underpin the coastal outcomes outlined in Figure 1. The article concludes by highlighting key considerations for instituting transformative governance innovations necessary to secure a sustainable future for coastal communities. The framework could be readily adapted and applied with little modification to non-coastal geographic settings and sustainability issues.

\section{Transformative Innovation for Coastal Sustainability}

A fundamental step-change in prevailing business and technology development and in underlying societal values and institutional practices is needed to navigate a way out of the global sustainability crisis. Transformative innovation involves system-wide changes in values, attitudes, behaviours, infrastructures and institutions. Such transitions have taken place in the past, sometimes serendipitously and occasionally deliberately, and they are often evolutionary, rather than revolutionary [8]. They invariably involve a protracted struggle, because they break new ground and are difficult to comprehend, involve significant risky investment, lead to conflicts between incumbent and emergent actors and reshape infrastructural and institutional boundaries viz. the abolition of slavery, public health and education reforms, nuclear disarmament and the spread of democracy. The latter exemplifies the systemic changes required in a society that transitions from an autocratic to democratic regime, often only after protracted struggle. Similar to these examples, the sustainability crisis necessitates intentional and urgent transformative innovation. However, formidable obstacles stand in the way, including deep social inequity, political polarization and isolation, trenchant individualism, rampant materialism, entrenched vested interests, institutional rigidity, pre-existing technological infrastructures and markets and established practices and incentives that encourage unsustainable development [9-13].

Rotmans et al. [8] identify four stages of transformative innovation: (i) prolonged pre-development in niche settings; (ii) "take off" in which momentum builds; (iii) "breaking through" conflict with existing interests and systems and overcoming lock-in in prevailing economic, political, institutional, infrastructural, cognitive and ideological arenas; and (iv) stabilization of the transformed system. Different strategies are needed for each stage. In the first two stages, strategies are needed that create safe spaces and open up opportunities for unhindered visioning, experimentation, network building and social learning, e.g., subsidies for sustainability research coupled with deliberative processes that engage diverse actors and networks. Formal and informal institutional pressures need to be exerted on unsustainable regimes and practices. In the third and fourth stages, institutional support is needed to facilitate the diffusion of emerging innovations; and systematic monitoring, lesson learning and institutional reform need to take place to mainstream resultant innovations [12]. The Dutch government sought to bring about transformative change through a program of transition management in reforming its energy systems in the early 2000s and through its fourth National Environmental Policy Plan [8].

Transformative innovation for sustainability needs to take place on multiple fronts and scales through diverse pathways across governance episodes, processes and cultures [1,14-16]. Society chooses trajectories of change, as some pathways are closed down and others are opened up [17]. There is no panacea. Rather, novel approaches will need to be tailored for different circumstances. What works in Holland, for example, may not be transferable to countries with different 
socio-political, cultural, economic and ecological features. Nonetheless, transformative innovation necessitates new forms of engagement that include all principal governance actors $[18,19]$ in a range of practices that include vision building, purposeful experimentation, directed political action, public dialogue, deliberation and social learning and institutional capacity building and transmogrification. Crucially, such endeavours need to extend beyond conventional wisdom, prevailing vested interests and incentives to encompass new voices and ideas through open discursive processes that can construct a shared vision of a sustainable future [19-22]. It is imperative to recognize the inherently cultural and socio-political nature of this process. All principal governance actors have important roles to play. However, governments have a catalytic role to play in creating enabling conditions that facilitate the transformation of societal expectations, behaviour and practices, because the coast is a common property resource under siege. According to Scrase et al., [12] government can play a particularly important role in mobilizing and shaping three key elements of transformative innovation: (i) building pathways through expansive social networks that can generate visions, beliefs, knowledge and understanding and capabilities to supersede unsustainable regimes and practices; (ii) enabling markets through purposeful experimentation to identify innovations with transformative potential and facilitate "take off" and "break through"; and (iii) strategic governance, so that deliberate, legitimate and accountable social choices can be made about preferred sustainability pathways. Key actors from civil society and the private sector also have pivotal roles to play and may be instrumental in catalysing transformative innovation for sustainability $[19,23]$. In fact, social movements and non-governmental organizations (NGOs) and community based organizations (CBOs) are already opening up discursive spaces between the boundaries of the state and citizens to address pernicious environmental and community development issues [24-26]. It suffices to say that a critical mass of social actors needs to be willing to engage in radical change even before the benefits of such an undertaking become obvious. Discursive processes that encompass visioning, experimentation, social learning and institutional reform and that cut across governance episodes, processes and cultures are needed to catalyse the sustainability transition. Deliberation is thus the key ingredient - the yeast-necessary to ferment transformative innovation for coastal sustainability.

\section{3. (Re)conceptualizing Coastal Management as A Transformative Practice of Deliberative Coastal Governance}

\subsection{Deliberation as the Foundation for Coastal Governance}

Deliberation takes place when communication induces reflection on values, preferences and interests in a non-coercive fashion; and authentic democracy exists to the extent that the reflective preferences of citizens determine collective outcomes [27]. In recent years, a deliberative turn in thinking and practice has taken place in diverse fields relevant to coastal management, notably in planning, e.g., [28,29], environmental governance, e.g., [30], and natural resource management, e.g., [31], and is also reshaping public dispute resolution, e.g., [32], public administration, e.g., [33], and political science, e.g., [34]. However, the coastal management literature makes little explicit reference to scholarship on deliberative democracy. A review of this literature reveals valuable insights for coastal management theory and practice and underpins the conceptual framework outlined here. 
Deliberative democracy scholars seek to address the failure of dominant governance modalities to resolve social dilemmas. According to Chambers [35]:

“... deliberation is debate and discussion aimed at producing reasonable, well-informed opinions in which participants are willing to revise preferences in the light of discussion, new information and claims made by fellow participants. Although consensus need not be the ultimate aim of deliberation and participants are expected to pursue their interests, an overarching interest in the legitimacy of outcomes (understood as justification to all affected) ideally characterizes deliberation."

Deliberative democracy encompasses a wide range of perspectives, but there is broad agreement on its essential features, see, e.g., [32,35-46]. Deliberation is a social communication process founded on non-coercive, reasoned and reflective dialogue that shapes and reshapes opinions, preferences and values. It is not simply talk or anaesthetized debate. It can include unruly and contentious communicative interactions in diverse forums. Importantly, it takes place in the public realm and addresses real social concerns that are differentially framed and imbued with contending values and perspectives. However, it often takes place outside formal political processes, which it aims to influence and even transform. It seeks to ensure open and accessible participation by all citizens affected by the outcome. It is therefore distinct from aggregative or representative political processes. Participants learn about the issues under consideration and engage in direct communication and robust problem analysis to resolve social dilemmas through inter alia attentive listening, careful consideration of contending values and interests, social learning, win-win conflict resolution and collective decision-making and action. Importantly, participants have equitable speaking status and deliberation takes place in safe spaces or arenas, where they can champion and challenge alternative points of view and co-create shared meaning and solutions. The power of good argument prevails rather than socio-economic or educational status. Deliberation seeks to produce binding decisions, but is dynamic and sustains opportunities for ongoing communication. In sum, according to Dryzek [39], deliberation needs to be authentic, inclusive and consequential:

"(Authentic) deliberation must induce reflection noncoercively, connect claims to more general principles and exhibit reciprocity. Inclusiveness applies to the range of interests and discourses present in a political setting. ... Consequential means that deliberative processes must have an impact on collective decisions or social outcomes. ... A polity with a high degree of authentic, inclusive and consequential deliberation will have an effective deliberative system" [39].

The prerequisites or conditions for authentic, inclusive and consequential deliberation are very demanding on citizens and societal institutions. It can be argued that deliberative democracy is idealistic and impractical, because of the difficulties of engaging citizens in authentic discursive processes in a world characterized by inter alia inequity, divergent dialogical competencies, dominant governance processes and ruling elites. Deliberation might even be harmful, because of high transaction costs to participate, the possibility of disempowering participants if it raises expectations that can't be met and the potential for co-optation, whereby minority groups are won over by more dominant interests. These concerns must be taken seriously and are the focus of attention by 
deliberative democracy scholars. Many argue persuasively that deliberation is both a normative and practical imperative, because the foundations of contemporary citizenship and democracy are weak [47-49]. Deliberation can help to address the citizenship deficit, i.e., the erosion of civil society and civic engagement, which prevails in many democracies. Evidence of this deficit is reflected in diverse studies that show a decline in social capital, political engagement and civic attitudes and competencies [47,48,50,51]. Deliberative processes can also help to overcome the democratic deficit, which describes the inability of prevailing democratic institutions, including governments and social institutions, to translate democratic rhetoric into reality [33,47,52]. Citizenship and democratic deficits are inter-linked and are significant issues for contemporary democracies, because they tend to be mutually reinforcing and undermine the health and stability of political systems. Yet, people demonstrate a greater willingness to engage in deliberative processes than is commonly realized (see, e.g., [53]). The promise of deliberation is to overcome the citizenship and democratic deficits that emasculate prevailing governance institutions. This potential is increasing with the democratization of knowledge through, among other things, the worldwide web and exponential increase in the use of diverse social media. Deliberative democracy, thus, has considerable potential to stimulate the transformative innovation that is necessary to confront the sustainability crisis (see, e.g., [26,34,54-56]). However, many obstacles need to be faced if the promise is to be realized. Developing a practice of deliberative coastal governance is, thus, a compelling, but radical, undertaking that redefines the nature and practice of coastal management. Such a practice will help to stimulate transformative innovations that chart new sustainability pathways and resolve the coastal problématique.

\subsection{Towards a Practice of Deliberative Coastal Governance}

The framework presented in Figure 2 outlines a series of coastal and process outcomes central to the pursuit of coastal sustainability. The deliberative foundation of process outcomes underpins the coastal outcomes outlined by Olsen and colleagues (see Figure 1). Four Orders of Outcomes are distinguished. They are interconnected, but progress sequentially, with first order outcomes providing an enabling platform for realizing second, third and fourth order outcomes. They do not progress in a linear or step-wise sequence, but rather, are likely to transition organically from first to fourth order outcomes with important links and feedback loops. The deliberative or process outcomes are the platform for realizing intermediate and end coastal outcomes. This deliberative outcomes approach was developed primarily on the basis of a review of the deliberative democracy literature, notably the writings of Dryzek [27,34,38,39], Fischer [25,54,57], Fung [44,58,59] and Fung and Wright [60,61] and adaptation of a framework developed by Carcasson [62].

The first order process outcomes develop the human and social capital upon which the other process and coastal outcomes are ultimately built. They comprise issue learning and improved democratic attitudes and skills. Together, they establish an educational platform to cultivate the enabling conditions for implementing coastal governance measures. The second order process outcomes are community-oriented action - in which individual and community interests are aligned through deliberation and improved institutional decision-making-with attention focused on the role of deliberation in improving the decision-making capacity of governmental and social institutions. These second order process outcomes are difficult to realize unless prior investment is made in the first order 
process outcomes. They are foundational for achieving the second order coastal outcomesimplementation through behavioural change. The third order process outcome is improved problem-solving ability within a community-reflecting the potential of deliberation to enhance community capacity to address pernicious coastal issues. Improved community problem-solving enables realization of specific ecological, economic and socio-cultural goals - the third order coastal outcome. The fourth order process outcome is collaborative communities-which sustain deliberative processes of inclusive dialogue, visioning, negotiation and co-operation. This ongoing ability to work togetherwithin and between communities at different levels and scales in an inclusive and discursive manneris key to navigating towards the fourth order coastal outcome of sustainable coastal development.

Figure 2. Deliberative coastal governance.

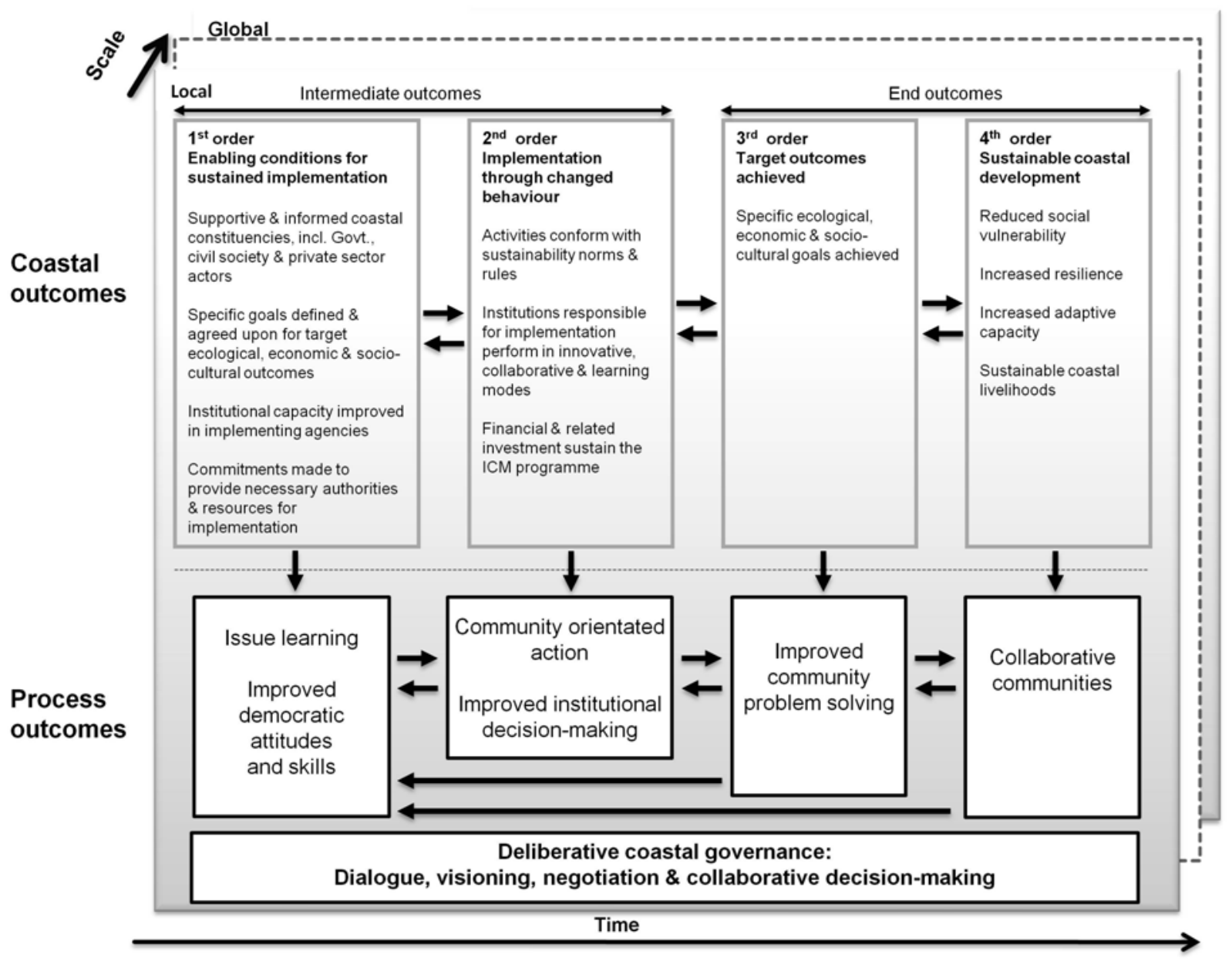

The term "community" is intentionally used, even though it is a complex, evolving and much-debated and even maligned concept. Community is used here to include communities of common interest, such as a religious community or the scientific community and place-based or territorially defined communities. More specifically, a community is:

"any network of ongoing relatively stable relationships among people holding diverse views, but with at least some base of shared values and ethical norms; some degree of caring, trust and collaborative activity; working through channels of communication; and carrying out certain ritual-like activities that have the effect of affirming the relationships" [63]. 
Communities encompass much more than a collection of common interests, actors and institutions. They are the crucible for social relationships and are permeated with and shaped by history, identity, mutuality, plurality, autonomy, participation, diversity, integration and collaboration [63-66]. Contemporary communities are typically heterogeneous and dynamic and encompass remarkably divergent values, interests and relationships. They are located within layers of institutional complexity that make it essential to consider interactions within and between communities and to recognize problems of fit between societal institutions and the natural systems within which they are embedded. Making collective decisions for sustainability in modern societies is consequently fraught and raises the long-standing conundrum about how to reconcile individual and community interests (see, e.g., [66]). Community is the arena within which we seek to understand and define our individual and collective rights and responsibilities. It is the locus of human identity, livelihood, culture, social interaction and political action. People identify with the places they live. Politics are territorially bound-with power and authority connected to locality at different scales. Economic value is attached to place, intersecting with socio-cultural, political and ecological dimensions. More fundamentally, community is an ethical construct - it is where and how we frame our meaning and purpose as human beings. Given the heterogeneity of extant communities and the absence of universal moral norms, community members need to work together to agree on the ethical principles that frame individual and community life. Community building is, thus, an ongoing and evolving social process based on self-conscious ethical reflection and democratic deliberation [63].

The question then is what kind of community is desirable, how should it be built, by whom and at what scale? Deliberation is the key ingredient for enabling people to work together to define and build the kind of community that best meets their interdependent needs now and into the future. The coastal problématique, therefore, needs to be addressed in community involving real people in real places addressing real issues in real time. Coastal governance is, therefore, neither a technical, nor an abstract undertaking. Fundamentally, it should be a discursive process that is historically located and defines the genius loci, socio-political, cultural, economic and ethical character of coastal communities. As explained by Glavovic [1], many local coastal communities are engaged in innovative episodes of collective action that challenge, but are nullified, by dominant governance processes and cultures that foster unsustainable practices. The transition towards coastal sustainability necessitates alignment between these local community episodes and larger scale governance processes and cultures. Consequently, there is no fixed temporal or spatial scale that is singularly appropriate for coastal governance. Charting a course towards coastal sustainability requires coherent innovations in governance episodes, processes and cultures. Such innovations will only occur when marginalised social groups and communities are included in dominant governance discourses and practices and innovation and social learning occur within and between coastal communities at all scales.

\subsubsection{First Order Process and Coastal Outcomes}

\subsubsection{Issue Learning}

Better understanding of coastal issues is the starting point for developing the enabling conditions for coastal governance. The deliberative process can help in a number of ways to deepen and extend issue 
learning by engaging coastal stakeholders and citizens in a more direct and reflective manner than is typical of dominant governance processes. Coastal issues are poorly understood, because (i) traditional scientific disciplines do not foster the holistic understanding that is necessary to address coastal sustainability issues and coastal stakeholders are alienated from processes that improve understanding about these issues and (ii) endeavours to translate scientific understanding into sound public policy often obfuscate understanding and exacerbate, rather than resolve, coastal conflicts [67]. With regard to the first problem, deliberation can open up the knowledge building process to a range of voices and inculcates a more complete understanding of the coast by integrating disciplinary understanding and scientific and non-scientific perspectives. There has been an exponential increase in information available about the coast since the advent of the worldwide web. However, coastal stakeholders are not well-positioned to know how to judge the quality of this information or how to synthesize and integrate it into common practice. Deliberative processes can provide forums for information management and social learning. Moreover, deliberative processes can help to reframe traditional scientific discourse, which is typically balkanized and separated from other forms of knowledge, discipline-bound, geared towards reductionism and posits a linear, equilibrium-centred view that is inappropriate for understanding the complexity of environmental issues [68]. Deliberation can counter the tendency to frame coastal issues as the domain of experts and help to bridge gaps within and between science and local and traditional knowledge. In summary, deliberation can have a significant positive educational impact for all involved [36,37,42,44,61]. Participants in deliberative processes voice their hopes, concerns and preferences, actively exchange ideas and listen empathetically to the preferences and views of others, including scientists and other specialists and, consequently, can begin to clarify, understand and refine their views and better understand one another's perspectives on issues under discussion. Bringing together diverse parties can thus create new and extend existing knowledge about coastal issues.

With regard to the second issue - integrating understanding about coastal issues into public policy and decision-making - the deliberative process can help inter alia to expose and address directly the negative consequences of the politicization of science, whereby science can be used as an adversarial weapon to bolster particular political interests or agendas, frustrating social learning [69]. At worst, some communication can be intentionally geared towards misinformation and polarization. Deliberative processes can help to engage science and other forms of knowledge as a means for monitoring, evaluation and social learning, ensure that knowledge building is based on a thorough review of relevant data and expose underlying values and political differences that underpin different social choices [70]. Deliberation can also help to counter public and political communication practices that focus on image and strategic positioning, rather than advancing public understanding of coastal issues.

Extensive deliberation is not necessary if the causes of a coastal problem are well-known, potential impacts are obvious, scientific uncertainty is low and there is little ambiguity about the issue and how it should be resolved. In some cases, investment in research will reduce scientific uncertainty. There are also circumstances when deliberation is inappropriate, e.g., in the immediate aftermath of a coastal disaster when there is a premium on efficient marshalling of resources to rescue injured people and stabilise the situation. However, many coastal issues are aptly characterised as "wicked problems" that feature deep uncertainty, ambiguity and contradictory and changing requirements that are not readily 
discernible. Moreover, promising solutions may lead to even more intractable problems. There are no panaceas for wicked problems. Deliberation is necessary to build a common understanding of such problems [1].

\subsubsection{Improved Democratic Attitudes and Skills}

Cultivating democratic dispositions and competencies is essential for creating the enabling conditions for coastal governance. Deliberation can have a positive psychological impact on participants and bolster political empowerment and efficacy [27,34,36,37,40,43,45,71]. It can help participants become better democratic citizens. It develops political sophistication by sparking interest and building trust, respect and empathy. Ultimately, it fosters public spiritedness. Deliberative processes can help to deepen and expand participant's awareness and appreciation of the views of others. It can even increase tolerance for alternative views, as participants become more sensitive to the concerns of others and the wider community. Deliberative processes bring people together in ways that are not likely to occur otherwise; and help to overcome the isolation and polarization that prevails in modern society.

Deliberation cultivates skills, such as attentive listening, eloquence, rhetorical ability, empathy, courtesy, imagination and reasoning capacity [37,42,43,45,72]. It helps to improve communication and judgment skills and facilitates better group decision-making, as participants seek to understand and address shared concern about complex public issues. Deliberation enables people to understand one another better, overcome misunderstandings and more effectively deal with differences. Well-developed democratic skills help to facilitate open and honest dialogue and improve relationships. Deliberation can thus help to clarify the underlying causes and nature of conflict and to enable participants to identify and develop mutually beneficial solutions. Enhancing democratic dispositions and skills is urgently needed in the context of politics-as-usual, where public involvement is commonplace, but authentic participation is inhibited, public debate is polarized and safe arenas for inclusive deliberation are rare. Deliberation can thus be an antidote to the deep pessimism and negative perceptions common amongst citizens and officials about public involvement in community decision-making. It would be naive to think that improving democratic attitudes and skills is a simple endeavour. However, deliberation is a necessary platform for democratic practice and helps to build the human and social capital necessary for cultivating the enabling conditions for coastal governance.

\subsubsection{Enabling Conditions for Sustained Implementation}

Olsen and colleagues [2-7] elaborate on the first order coastal outcome requirements to facilitate the requisite behavioural changes that mark the second order (see Figure 2). The first order process outcomes help citizens, coastal actors and key constituencies become better informed about coastal issues and, consequently, supportive of and engaged in governance endeavours with transformative potential. Deliberation helps to secure agreement on specific sustainability goals and target outcomes. Deliberation is also foundational for developing institutional capacity and securing commitments to provide necessary authorities and resources for implementation. 


\subsubsection{Second Order Process and Coastal Outcomes}

\subsubsection{Community-Oriented Action}

Community-oriented action is hampered inter alia by insidious individualism and political alienation and isolation. Deliberation helps participants to develop a sense of common concern that transcends narrow self-interest and embraces community interests. Deliberation can thus become a powerful counterweight to dominant governance processes. It can help participants overcome biases and parochialism, so that they begin to see the multiple possible framings of coastal problems and craft community-oriented solutions. This potential to reconcile self-interest and wider community interests is central to the arguments of deliberative democrats, dating back to the seminal work of Alexis de Tocqueville ([73] originally published 1835-1840) and John Dewey, e.g., [74].

\subsubsection{Improved Institutional Capacity and Decision-Making}

Deliberation helps to improve the capacity and decision-making efficacy of social institutions [27,37,43,45,46,75,76]. Deliberative processes enable key social institutions to look beyond superficial symptoms to the underlying root causes and drivers of unsustainable practices. They help to overcome insularity and compartmentalization and improve coordination and cooperation. By opening up opportunities for engagement, these processes diversify perspectives and, thus, expand the limited views of like-minded people or the perpetuation of us-versus-them attitudes that can bedevil insular institutions. Deliberation can help community members develop a shared sense of empowerment and possibility that is quite distinct from actions that might be taken on a community's behalf by the state.

Deliberation offers many benefits to modern governments [33,34,42,44-46,59,72,75,77]. It can help to build the capacity of government and improve decision-making for sustainability and, thus, improve the quality of governance. In particular, deliberative processes open up opportunities for meaningful public participation in government decision-making. Deliberation can help marginalized citizens engage in the political process and, thus, reduce political inequality. It can help to improve the efficacy and justice of public decisions, legitimize social choices, generate wiser decisions and yield positive and enduring social outcomes. Compared to dominant governance modalities, deliberative processes offer better prospects for addressing the complex pastiche of sustainability problems confronting contemporary society $[26,34,54]$ and help to facilitate the transition towards the second order coastal outcomes described by Olsen and colleagues [2-7].

\subsubsection{Implementation through Changed Behaviour}

Deliberation is needed to define sustainability goals and target outcomes and fosters community-oriented action and behaviour consonant with community norms and rules. Improved institutional capacity and decision-making is essential to chart a course towards sustainability and, hence, the imperative for institutional innovation, collaboration and social learning and inter alia sustained financial and other enabling investment. 


\subsubsection{Third Order Process and Coastal Outcomes}

\subsubsection{Improved Community Problem-Solving}

Higher levels of government often assume responsibility for identifying and implementing community solutions [78]. Alternatively, technical solutions are proffered by external experts, professionals or scientists. At its best, deliberation can help participants develop a shared community vision, engage in meaningful dialogue, negotiate, find common ground and implement innovative solutions for pressing community problems [27,34,36-38,43-46,71]. This does not mean that self-interest has no place in deliberative practice [79]. Deliberation opens up opportunities for deeper empathy, understanding and increased tolerance, even when conflict persists. Importantly, participating in deliberative processes can lead to self-reinforcing positive feedback that encourages innovative deliberative interaction to solve community problems. Community problem-solving is, thus, much more than a technical challenge or a procedural endeavour to coordinate abstract interests, actors and institutions. It is first and foremost a process for defining and working out community relationships and obligations. It is, therefore, imperative to understand the historical, cultural, social and political milieu within which community problems are located. Deliberative design and problem-solving thus go beyond specifying institutional rules, regulations and practices to include understanding and working with cultural norms and rituals that are specific to particular communities. Indeed, the identities of actors, practices, institutions and the processes, through which meaning and relationships are defined, contested and potentially transformed, are discursively defined [25,57]. These social constructs may be less tangible than the technical issues and policy options under consideration, but they are nonetheless pivotal to shaping the social space of deliberation.

"Basic here is the interplay of power and difference in the making of social spaces and the microcultural politics of the interactions within them. ... Never socially neutral, space enables some actions - including the possibility of new actions - and blocks or constrains others. ... Social space, then, can be understood as woven together by a set of discursive relationships that determine the meanings and understandings of the identities within them. Through these discursive practices, the power relations of the surrounding societal context are brought into the social space. Toward this end, it is necessary to make explicate the less visible discursive power relations that permeate and produce these and other spaces" [25].

Fischer [25] goes on to point out that pivotal questions for understanding and discerning the nature and efficacy of deliberation — such as who should design and participate in these processes - or what do the people who participate bring into these processes? - can only be answered by entering the social space in situ, wherein those involved articulate the meaning(s) of the socio-political relationships (including class, race, gender, etc.) that shape deliberation. Empowering deliberative processes $[44,60,61]$ not only require support from above, but may also need active intervention to organize social space to involve and emancipate citizens who might otherwise not engage [25]. Viewing community problemsolving from this perspective raises important questions about the roles of key players in deliberative processes. Arguably, the most important actors in these processes are those from civil society, including social movements and non-governmental and community-based organizations, who open up 
new deliberative arenas or social spaces, to bridge and redefine the boundaries between formal institutional structures and governments, in particular, as well as the citizenry [23,25]. These intermediary spaces can facilitate discursive interactions that range from radical self-help to colonizing state power by transforming the relationships between citizens and government [61]. Community problem-solving is, therefore, an ongoing deliberative conversation by community members themselves. It cannot be engineered by experts from the outside or even by officials and/or elected representatives from the inside. Community members themselves need to explore discursively different ways of understanding and aligning their interests, prejudices and preconceptions relative to those of other community members through mutual influence, persuasion and reciprocity [63] without resorting to coercion. Scientists, experts, professionals, civic leaders, government officials and elected representatives have pivotal roles to play in community problem-solving. It should not, however, include unilateral imposition of solutions on a community [54]. Appropriate specialist roles include learning from and contributing to the community deliberation process. This can take place in diverse ways depending on who is making the contribution at which point in the conversation and ranges from informing to verifying, facilitating, championing, acting as an intermediary and legitimizing community decisions. Improved community problem-solving is foundational for achieving the target outcomes defined by Olsen and colleagues [2-7].

\subsubsection{Target Outcomes Achieved}

Community problem-solving is neither a simple nor a linear process. Difficult choices must be confronted that involve divisive questions about private and communal interests and short- and long-term risks, costs and benefits. Inevitably, there are winners and losers and simple trade-offs or optimal solutions are seldom possible. Solutions to one problem may generate novel and unanticipated problems elsewhere, sometimes far removed, from where a solution is implemented. Revealing the underlying drivers of a problem can expose latent conflict. Community problem-solving is, therefore, a complex, contested and enduring discursive process. However, with improved problem-solving capabilities, communities are better able to realize the sustainability goals and target outcomes they have agreed upon.

\subsubsection{Fourth Order Process and Coastal Outcomes}

\subsubsection{Building Collaborative Communities}

Coastal management and environmental governance scholarship stress the pivotal importance of understanding and overcoming cross-scale and multi-level barriers to sustainability. Deliberative democracy scholars similarly focus attention on discursive challenges and opportunities for resolving the social dilemmas that bedevil and interconnect communities at different scales and levels (see [34] for a synopsis). Communities are inherently embedded in a nested institutional hierarchy and empowering local community deliberation is, therefore, dependent upon support from higher level institutions, as well as emancipating discursive processes from within and below [25,26,34,57,58,60,61]. The challenge is to construct a multi-directional conversation within and between interdependent communities at different levels and scales, cognizant of the need to overcome dissonance between 
prevailing governance episodes, processes and cultures [1]. Building collaborative communities is, thus, a socio-political struggle that involves diverse actors and reaches from the local to global level. According to Somerville [80]:

“... in order to succeed, counter-hegemonic forces at neighbourhood level need to be integrated, both horizontally and vertically, within a distinctive movement at national, continental and even global level. At the same time, in order to be effective, this movement must engage strategically and democratically with dominant corporate and state power. The movement must operate within established institutions, in order to transform them, but it must also be autonomous, in order not to be co-opted into those institutions. ... it must be both a social movement, directly contesting established power as embodied in existing social institutions and a political movement, bringing together a diversity of actors, from different social contexts, in public arenas, in order to challenge established power at key sites and moments."

Significantly, there is evidence that deliberative processes can help participants make explicit their assumptions, views and interests and, in the process, reveal, address and even transcend scale and level interests and contests [24,26,34,55,81]. Deliberative processes, therefore, need to be designed to engage participants from different scales and levels so that scale- and level-relevant perspectives and issues are robustly explored and contending values, logics and interests are recognized. Institutional catalysts, filters, linkages and levers of change and adaptive networks are needed to initiate, facilitate and sustain trans-boundary deliberation. Open political institutions and innovative citizen-oriented processes and civic infrastructure - the formal and informal mechanisms that link different actors, networks, institutions and communities - are needed to ferment cross-scale and multi-level deliberation. Some institutions function as pathfinders and open up new deliberative spaces. Others function as anchors, enabling deliberation and providing vital counter-hegemonic activity and catalysing and sustaining discursive momentum. Others function as bridges to link cross-level and -scale formal and informal institutions. Still, others function as watchdogs to monitor deliberative authenticity. Ultimately, a plurality of institutional forms and interactions is needed to facilitate cross-scalar and multi-level integrated deliberation. Social institutional processes and incentive structures need to be aligned with the cross-scalar and multi-level coastal ecosystems within which coastal communities are embedded. The precise institutional configuration appropriate to particular circumstances will, therefore, need to be discursively determined.

\subsubsection{Sustainable Coastal Development}

The fourth order coastal outcome is conventionally framed as an optimal balancing of ecological, economic and socio-cultural imperatives (see Figure 1). However, this conceptualization of sustainable coastal development is fundamentally flawed. Seeking to trade off sustainability imperatives in search of optimality is a chimera in the context of coastal systems that are open, coupled, complex, unpredictable and characterized by ecological limits, interactive non-linear system dynamics and emergent properties [82]. Moreover, sustainability is culturally framed in various, contested and evolving ways that reflect the heterogeneous character of stakeholders, citizens and communities $[83,84]$. 
It is, therefore, suggested that four distinct, but interrelated, sustainability characteristics should be used by communities to gauge progression beyond specific sustainability goals and target outcomes. The meaning of each term and their interrelationships need to be defined and appropriated in the context of real-world deliberation. First, coastal communities face escalating disaster risk in this era of global change. Natural hazards, such as intense coastal storms, become disasters when societal coping capacity fails. Those hardest hit are the socially vulnerable - people with limited ability to anticipate, resist, cope with and recover from hazard events [85,86]. A disaster thus becomes unavoidable in the context of social vulnerability [87], viz. post-Katrina New Orleans. Vulnerability is shaped inter alia by differential exposure, sensitivity to impacts and the capacity to reduce risks [88]. Importantly, exposure, sensitivity and coping capacity at the local level are shaped by wider societal characteristics and drivers [89], such as social inequity, political marginalization and institutional racism. Reducing social vulnerability is, therefore, the first precondition for sustainable coastal development. Second, sustainable communities are resilient, i.e., they are able to withstand external shocks, including natural hazard events and social, economic or political shocks, as well as slow-onset change and display inter alia self-organizing capabilities and learning and adaptive capacities [90,91]. Resilience and vulnerability are different, but related, concepts for understanding how people and social-ecological systems deal with change. Together, these concepts and the associated scholarship that has to some extent been artificially divided, provide an important basis for gauging the transition towards sustainability [92,93]. Third, adaptive capacity is a related concept that has been used inter alia by the Intergovernmental Panel on Climate Change [94] to describe the ability or potential of a system to respond successfully to climate variability and change. There is a rich and contested scholarship on vulnerability, resilience and adaptive capacity. Focused attention on these concepts is constructive, because they are different manifestations of the capability to deal with changing circumstances, stresses and shocks in complex social-ecological systems [95] and are indicative of the level of sustainability of coastal communities. Fourth, sustainable coastal livelihoods is a useful construct for gauging sustainable coastal development, because it integrates and extends insights gained by focusing on vulnerability, resilience and adaptive capacity alone. A livelihood can be deemed sustainable when it copes with and recovers from stresses and shocks and maintains or enhances capabilities and assets, both now and in the future, without undermining the natural resource base [96]. The sustainable livelihood concept focuses attention on the dynamic vulnerability context within which communities live and which shapes opportunities for using available assets and capabilities. It also highlights the role played by governance and social institutions in mediating access to these assets and how they shape pursuit of alternative livelihood strategies to achieve desired livelihood outcomes. Sustainable coastal development can, thus, be discursively framed by the extent to which social vulnerability is reduced, resilience and adaptive capacity are increased and coastal livelihoods are sustainable.

\section{Conclusions}

The framework outlined in this article defines coastal governance as a cultural and socio-political deliberative process. It underscores the need for communities to confront the coastal problématique through trans-boundary discursive interrogation and action. It builds upon and extends the prevailing approach to coastal management, which tends to emphasize ecological thresholds and social-ecological 
interconnections, optimal trade-off of sustainability imperatives and elevates the role of scientists and coastal managers over coastal citizens. Creating conditions conducive for a transformative practice of deliberative coastal governance is an immensely challenging and even radical undertaking. Charting a course beyond the coastal sustainability crisis necessitates transmogrification of prevailing business and technology and underlying societal values, infrastructures, institutions and practices. New pathways need to be purposefully explored, markets enabled and strategic governance processes mobilized to engage coastal communities in discursive practices that transcend and align governance episodes, processes and cultures. Communities will face many difficult questions in their efforts to institutionalize empowering modalities of deliberative coastal governance. For example, how does one construct inclusive safe discursive spaces - the niche settings within which transformative innovations can be developed to the point of "take off'? How can discursive trans-boundary experiments be designed, implemented and sustained to break through dominant structures and processes to become mainstream? Who should design and participate in these processes, and what do the people who participate bring into these processes? This framework provides pedagogical direction for framing and addressing such questions.

Deliberation stimulates and facilitates social learning about coastal issues and improves democratic dispositions and competencies. It builds the human and social capital that is crucial for cultivating the enabling conditions and behavioural change necessary for implementing effective coastal governance measures. Deliberation helps to align individual and community interests and actions and improves the decision-making capacity of governmental and social institutions. Deliberation builds the capacity of communities to solve vexing coastal problems and, thus, realize agreed interconnected ecological, economic and socio-cultural goals and target outcomes. Deliberation builds collaborative communities that can sustain trans-boundary dialogue, visioning, negotiation and cooperation in pursuit of truly sustainable coastal development.

The fundamental challenge is to democratize coastal management through deliberative capacity building. Again, the work of Dryzek [39] is instructive. Coastal governance can be conceived as a process of deliberative capacity building. The more authentic, inclusive and consequential deliberation is, the more democratic the coastal governance process. The institutional architecture for building such capacity should not be prescribed, but needs to be designed and constructed discursively by coastal communities. Communities in non-coastal settings could also apply with little modification this framework to better understand and innovatively address a wide range sustainability issues.

In conclusion, coasts are the frontline of the global sustainability crisis. How this crisis is handled by coastal communities will chart the course for future human and planetary well-being. Two key considerations need to be highlighted. First, conflict needs to be recognized as an inevitable and ever-present reality that must be addressed in a constructive manner through empowering discursive practices. Deliberation, as described here, provides a vital medium for resolving the dialectical tension between conflict and collaboration. Secondly, it needs to be recognized that a transformative practice of deliberative coastal governance has to be a long-term endeavour. It cannot be a one-off conversation; otherwise, it will reinforce the failure of commonplace isolated and short-term governance episodes that are overwhelmed by governance processes that perpetuate unsustainable business-as-usual practices. In addition, it must comprise trans-boundary, intra- and inter-generational 
communicative interactions through which the stories of coastal communities are courageously written, narrated, rewritten and retold over time.

\section{Acknowledgments}

The financial support of the New Zealand Earthquake Commission is gratefully acknowledged, but this research is independent of that agency. I appreciate Paul Schneider's assistance in preparing the figures. Constructive reviewer suggestions are gratefully acknowledged.

\section{Conflict of Interest}

The author declares no conflict of interest.

\section{References}

1. Glavovic, B.C. The Coastal Innovation Paradox. Sustainability 2013, submitted for publication.

2. Olsen, S.B. Assessing Progress towards Goals of Coastal Management. Coast. Manage. 2002, 30, $325-345$.

3. Olsen, S.B. Frameworks and Indicators for Assessing Progress in Integrated Coastal Management Initiatives. J. Ocean Coastal Manage. 2003, 46, 347-361.

4. GESAMP. The Contributions of Science to Integrated Coastal Management; Reports and Studies No. 61; Food and Agriculture Organisation of the United Nations: Rome, Italy, 2006.

5. UNEP/GPA. Ecosystem-based Management: Markers for Assessing Progress; UNEP/GPA: The Hague, The Netherlands, 2006.

6. National Research Council. Increasing Capacity for Stewardship of Oceans and Coasts: A Priority for the 21st Century; National Academy Press: Washington, DC, USA, 2008.

7. Olsen, S.B.; Page, G.G.; Ochoa, E. The Analysis of Governance Responses to Ecosystem Change: A Handbook for Assembling a Baseline; LOICZ R\&S Report No. 34; LOICZ: Geesthacht, Germany, 2009.

8. Rotmans, J.; Kemp, R.; van Asselt, M. More Evolution than Revolution: Transition Management in Public Policy. Foresight 2001, 3, 15-31.

9. Kok, M.T.J.; Vermeulen, W.; Faaij, A.; de Jager, D. Global Warming and Social Innovation: The Challenge of a Climate-Neutral Society; Earthscan: London, UK, 2002.

10. Elzen, B.; Geels, F.; Green, K. System Innovation and the Transition to Sustainability: Theory, Evidence and Policy; Edward Elgar: Cheltenham, UK, 2004.

11. Jordan, A.J.; Lenschow, A. Innovation in Environmental Policy? Integrating the Environment for Sustainability; Edward Elgar: Cheltenham, UK, 2008.

12. Scrase, I.; Stirling, A.; Geels, F.W.; Smith, A.; van Zwanenberg, P. Transformative Innovation: A Report for the Department for Environment, Food and Rural Affairs; University of Sussex, SPRU-Science and Technology Policy Research: Brighton, UK, 2009.

13. Smith, A.; Voß, J.-P.; Grin, J. Innovation studies and sustainability transitions: the allure of the multi-level perspective and its challenges. Res. Policy 2010, 39, 435-448.

14. Coafee, J.; Healey, P. "My voice: My place": Tracking transformations in urban governance. Urban Studies 2003, 40, 1979-1999. 
15. Healey, P. Creativity and urban governance. Policy Studies 2004, 25, 87-102.

16. Healey, P. Transforming Governance: Challenges of Institutional Adaptation and a New Politics of Space. Eur. Plan. Stud. 2006, 14, 299-320.

17. Stirling, A. "Opening up" and "Closing Down": Power, Participation and Pluralism in the Social Appraisal of Technology. Sci. Technol. Hum. Val. 2008, 33, 262-294.

18. Hendriks, C.M. On Inclusion and Network Governance: The Democratic Disconnect of Dutch Energy Transitions. Public Admin. 2008, 86, 1009-1031.

19. Hendriks, C.M. Policy Design without Democracy? Making Democratic Sense of Transition Management. Policy Sci. 2009, 42, 341-368.

20. Leach, M.; Scoones, I.; Stirling, A. Governing epidemics in an age of complexity: narratives, politics and pathways to sustainability. Global Environ. Change 2010, 20, 369-377.

21. Leach, M.; Scoones, I.; Stirling, A. Dynamic Sustainabilities: Technology, Environment and Social Justice; Earthscan Publications: London, UK, 2010.

22. Smith, A.; Stirling, A. The politics of social-ecological resilience and sustainable socio-technical transitions. Ecol. Soc. 2010, 15, 11.

23. Henderson, H. Social innovation and citizen movements. Futures 1993, 25, 322-338.

24. Velasquez, J.; Yashiro, M.; Yoshimura, S.; Ono, I. Innovative Communities: People-centred Approaches to Environmental Management in the Asia-Pacific Region; United Nations University Press: Tokyo, Japan, 2005.

25. Fischer, F. Participatory governance as deliberative empowerment: The cultural politics of discursive space. Am. Rev. Public Admin. 2006, 36, 19-40.

26. Goodin, R.E.; Dryzek, J.S. Deliberative impacts: The macro-political uptake of mini-publics. Politics Society 2006, 34, 219-244.

27. Dryzek, J.S. Deliberative Democracy and Beyond: Liberalism, Critics, Contestations; Oxford University Press: Oxford, UK, 2000.

28. Healey, P. Collaborative Planning: Shaping Places in Fragmented Societies; Macmillan: London, UK, 1997.

29. Innes, J.E.; Booher, D.E. Planning with Complexity: An Introduction to Collaborative Rationality for Public Policy; Routledge: New York, NY, USA, 2010.

30. Lemos, M.C.; Agrawal, A. Environmental governance. Annu. Rev. Environ Resources 2006, 31, 297-325.

31. Wondolleck, J.M.; Yafee, S.L. Making Collaboration Work: Lessons from Innovation in Natural Resource Management; Island Press: Washington, DC, USA, 2000.

32. Dukes, E.F. Resolving Public Conflict: Transforming Community and Governance; Manchester University Press: Manchester, UK, 1996.

33. Nabatchi, T. Addressing the citizenship and democratic deficits: the potential of deliberative democracy for public administration. Am. Rev. Public Admin. 2010, 40, 376-399.

34. Dryzek, J.S. Foundations and Frontiers of Deliberative Governance; Oxford University Press: Oxford, UK, 2011.

35. Chambers, S. Deliberative Democratic Theory. Annu. Rev. Political Sci. 2003, 6, 307-326.

36. Pateman, C. Participation and Democratic Theory; Cambridge University Press: Cambridge, MA, USA, 1970. 
37. Mansbridge, J. Beyond Adversary Democracy; Basic Books: New York, NY, USA, 1980.

38. Dryzek, J.S. Discursive Democracy: Politics, Policy and Political Science; Cambridge University Press: New York, NY, USA, 1990.

39. Dryzek, J.S. Democratization as deliberative capacity building. Comparative Political Studies 2009, 42, 1379-1402.

40. Benhabib, S. Democracy and Difference: Contesting Boundaries of the Political; Princeton University Press: Princeton, NJ, USA, 1996.

41. Bohman, J.; Rehg, W. Deliberative Democracy: Essays on Reason and Politic; MIT Press: Cambridge, MA, USA, 1997.

42. Elster, J. Deliberative Democracy; Cambridge University Press: Cambridge, UK, 1998.

43. Bohman, J. Public Deliberation: Pluralism, Complexity, and Democracy; MIT Press: Cambridge, MA, USA, 2000.

44. Fung, A. Empowered Participation: Reinventing Urban Democracy; Princeton University Press: Princeton, NJ, USA, 2004.

45. Guttman, A. Thompson D. Democracy and Disagreement; Harvard Belnap Press: Cambridge, MA, USA, 1996.

46. Guttman, A.; Thompson, D. Why Deliberative Democracy? Princeton University Press: Princeton, NJ, USA, 2004.

47. Durant, R.F. The democracy deficit in America. Polit. Sci. Q. 1995, 100, 25-47.

48. Macedo, S. Democracy at Risk: How Political Choices Undermine Citizen Participation, and What We Can Do About it; Brookings Institution Press: Washington, DC, USA, 2005.

49. Dalton, R.J. Citizen Politics: Public Opinion and Political Parties in Advanced Industrial Democracies; CQ Press: Washington, DC, USA, 2006.

50. Putnam, R.D. Bowling Alone: The Collapse and Revival of American Community; Simon \& Schuster: New York, NY, USA, 2000.

51. Stolle, D.; Hooghe, M. Inaccurate, Exceptional, One-sided or Irrelevant? Brit. J. Political Sci. 2004, 35, 149-167.

52. Stivers, C. Governance in Dark Times: Practical Philosophy for Public Service; Georgetown University Press: Washington, DC, USA, 2008.

53. Neblo, M.A.; Esterling, K.M.; Kennedy, R.P.; Lazer, D.M.J.; Sokhey, A.E. Who wants to deliberate-and why? Am. Political Sci. Rev. 2010, 104, 566-583.

54. Fischer, F. Citizens, Experts and the Environment: The Politics of Local Knowledge; Duke University Press: Durham, NC, USA, 2000.

55. Baber, W.F.; Bartlett, R.V. Deliberative Environmental Politics: Democracy and Ecological Rationality; MIT Press: Cambridge, MA, USA, 2005.

56. Gupte, M.; Bartlett, R.V. Necessary preconditions for deliberative environmental democracy? challenging the modernity bias of current theory. Global Environ. Politics 2007, 7, 94-106.

57. Fischer, F. Reframing Public Policy: Discursive Politics and Deliberative Practices; Oxford University Press: Oxford, UK, 2003.

58. Fung, A. Recipes for Public Spheres: Eight Institutional Design Choices and their Consequences. J. Political Philosophy 2003, 11, 338-367.

59. Fung, A. Varieties of participation in democratic governance. Public Admin. Rev. 2006, 66, 66-75. 
60. Fung, A.; Wright, E.O. Deepening democracy: Innovations in empowered local governance. Politics Society 2001, 29, 5-41.

61. Fung, A.; Wright, E.O. Deepening Democracy: Institutional Innovations in Empowered Participatory Governance; Verso: New York, NY, USA, 2003.

62. Carcasson, M. Beginning with the End in Mind: A Call for Goal-Driven Deliberative Practice; Occasional Paper, No. 2; Center for Advances in Public Engagement: New York, NY, USA, 2009.

63. Cooper, T.L. Building ethical community. Am. Rev. Public Admin. 2011, 41, 3-22.

64. Selznick, P. The Moral Commonwealth: Social Theory and the Promise of Community; University of California Press: Berkeley, CA, USA, 1992.

65. Etzioni, A. The Essential Communitarian Reader; Rowman \& Littlefield: Lanham, MD, USA, 1998.

66. Etzioni, A.; Volmert, A.; Rothschild, E. The Communitarian Reader: Beyond the Essentials; Rowman \& Littlefield: Lanham, MD, USA, 2004.

67. Glavovic, B.C. ICM as a Transformative Practice of Consensus Building: A South African Perspective. J. Coastal Res. 2006, 39, 1706-1710.

68. Stern, P.C. Deliberative methods for understanding environmental systems. BioScience 2005, 55, 976-982.

69. Nelkin, D. Controversy: Politics of Technical Decisions; Sage: Beverly Hills, CA, USA, 1984.

70. Ozawa, C. Recasting Science: Consensual Procedures in Public Policy Making; Westview Press: Boulder, CO, USA, 1991.

71. Barber, B. Strong Democracy: Participatory Politics for a New Age; University of California Press: Berkeley, CA, 1984.

72. Gastil, J.; Levine, P. The Deliberative Democracy Handbook: Strategies for Effective Civic Engagement in the Twenty-First Century; Jossey-Bass: San Francisco, CA, USA, 2005.

73. De Tocqueville, A. Tocqueville: Democracy in America (Translated by A. Goldhammer); The Library of America: Washington, DC, USA, 2004.

74. Dewey, J. The Public and its Problems; Holt: New York, NY, USA, 1927.

75. Young, I.M. Inclusion and Democracy; Oxford University Press: New York, NY, USA, 2000.

76. Boyte, H.C. Reframing Democracy: Governance, Civic Agency, and Politics. Public Admin. Rev. 2005, 65, 536-546.

77. Sirianni, C. Investing in Democracy: Engaging Citizens in Collaborative Governance; Brookings Institute Press: Washington, DC, USA, 2009.

78. Moore, M.H. Break-through Innovations and Continuous Improvement: Two Different Models of Innovative Processes in the Public Sector. Public Money Manage. 2005, 25, 43-50.

79. Mansbridge. J.; Bohman, J.; Chambers, S.; Estlund, D.; Føllesdal, A.; Fung, A.; Lafont, C.; Manin, B.; Martí, J.L. The Place of Self-Interest and the Role of Power in Deliberative Democracy. J. Political Philosophy 2010, 18, 64-100.

80. Somerville, P. Community governance and democracy. Policy Politics 2005, 33, 117-144.

81. Dore, J.; Lebel, L. Deliberation and scale in mekong region water governance. Environ. Manage. 2010, 46, 60-80.

82. Glavovic, B.C. Ocean and coastal governance for sustainability: imperatives for integrating ecology and economics. In Ecological Economics of the Oceans and Coasts; Patterson, M.G., Glavovic, B.C., Eds.; Edward Elgar: Cheltenham, UK, 2008; pp. 313-342. 
83. Meadowcraft, J. Who is in charge here? Governance for sustainable development in a complex world. J. Environ. Policy Planning 2007, 9, 299-314.

84. Meadowcraft, J. What about politics? Sustainable development, transition management, and long term energy transitions. Policy Sci. 2009, 42, 323-340.

85. Wisner, B.; Blaikie, P.; Cannon, T.; Davis, I. At Risk: Natural Hazards, People's Vulnerability and Disasters, 2nd ed.; Routledge: London, UK, 2004.

86. Adger, W.N.; Hughes, T.P.; Folke, C.; Carpenter, S.R.; Rockström, J. Social-Ecological resilience to coastal disasters. Science 2005, 309, 1036-1039.

87. Hoffman, S.; Oliver-Smith, A. Catastrophe \& Culture; School of American Research Press: Santa Fe, NM, USA, 2002.

88. Adger, W.N. Vulnerability. Global Environ. Chan. 2006, 16, 268-281.

89. Smit, B.; Wandel, J. Adaptation, adaptive capacity and vulnerability. Global Environ. Chan. 2006, 16, 282-292.

90. Adger, W.N. Social and ecological resilience are they related? Prog. Hum. Geog. 2000, 24, 347-364.

91. Walker, B.H.; Salt, D.A. Resilience Thinking: Sustaining Ecosystems in a Changing World; Island Press: Washington, DC, USA, 2006.

92. Miller, R.; Osbahr, H.; Boyd, E.; Thomalla, F.; Bharwani, S.; Ziervogel, G.; Walker, B.; Birkmann, J.; van der Leeuw, S.; Rockström, J.; et al. Resilience and vulnerability: complementary or conflicting concepts? Ecol. Soc. 2010, 15, 11.

93. Turner, B.L. Vulnerability and resilience: coalescing or paralleling approaches for sustainability science? Global Environ. Chan. 2010, 20, 570-576.

94. Parry, M.; Canziani, O.; Palutikof, J.P.; van der Linden, P.J.; Hanson, C.E. Contribution of Working Group II to the Fourth Assessment Report of the Intergovernmental Panel on Climate Change; Cambridge University Press: Cambridge, MA, USA, 2007.

95. Gallopín, G.C. Linkages between vulnerability, resilience and adaptive capacity. Global Environ. Change 2006, 16, 293-303.

96. Chambers, R.; Conway, G. Sustainable Rural Livelihoods: Practical Concepts for the 21st Century; Discussion Paper 296; University of Sussex, Institute of Development Studies: Brighton, UK, 1991.

(C) 2013 by the authors; licensee MDPI, Basel, Switzerland. This article is an open access article distributed under the terms and conditions of the Creative Commons Attribution license (http://creativecommons.org/licenses/by/3.0/). 